\title{
JOURNAL.RU
}

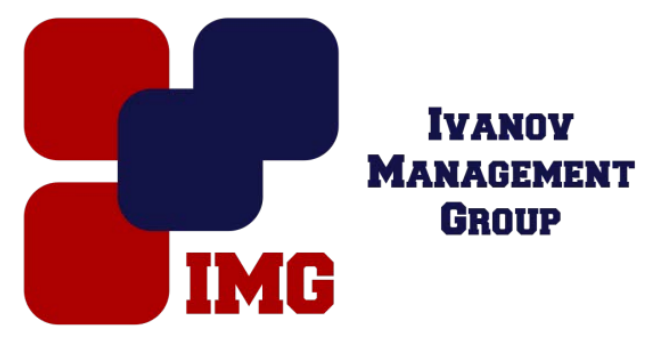

Медяник А.В., Тарабановская С.В. ГОУ ВПО ЛНР «Луганский начиональный университет имени Тараса Шевченко» Луганск, Украина

doi: 10.18411/lj-25-12-2016-3-15

idsp 000001:lj-25-12-2016-3-15

\section{Роль менеджера в формировании и развитии корпоративной культуры туристского предприятия}

Мастерство управлять является одним из самых сложных, поскольку касается взаимоотношений между людьми. Управление возникло вместе с людьми - при их желании совместно достигнуть поставленной цели для получения эффективных результатов необходимы планирование и координация действий участников.

Профессиональный и компетентный менеджер играет роль не только координатора и руководителя работников любого из предприятий, но и профессионалом в сфере формирования культуры его сотрудников. Именно различия и особенности этих сотрудников зачастую требуют индивидуального подхода и сопоставления их интересов между собой. Именно поэтому исследования в области формирования и развития корпоративной культуры всегда являются актуальными.

Вопросами управления персоналом, формирования корпоративной культуры, взаимоотношений сотрудников занимались многие известные ученые и специалисты как в области экономики, так и психологии, социологии и др. смежных наук $[1,3]$. Однако специфика каждой конкретного предприятия не позволяет применять одни и те же рекомендации при формировании корпоративной культуры. Именно поэтому необходимо выделить основные направления и задачи, которые должен учитывать или

выполнять менеджер при управлении персоналом и его взаимоотношениями.

Корпоративная культура - достаточно сложное явление. Основная сложность определяется природой человеческих отношений и самого человека как личности. Любое предприятие представляет собой группу людей, где каждый человек - личность, которая, как бы ни хотелось другим членам данной группы, является уже устойчивой системой мировоззренческих, психологических и поведенческих признаков. Сама же природа человеческих отношений построена на общении, в которое входят

три составляющие: коммуникативная сторона (обмен информацией между людьми); интерактивная сторона (организация взаимодействия между 
индивидами); перцептивная сторона (процесс восприятия друг друга партнёрами по общению и установлению взаимопонимания). Таким образом, можно говорить об общении как организации совместной деятельности и взаимоотношении включённых в неё людей.

Большую часть времени работающий человек проводит на работе, поэтому так важно руководителю (менеджеру) любого уровня поддерживать гармонию внутри предприятия. В связи с этим менеджеру необходимо выполнить ряд непростых задач, главными из которых являются следующие [2]:

1. сделать коллектив сплочённым и эффективным, т.е. таким, где каждый человек, независимо от его должности, положения и социального статуса, осознаёт, что его работа важна для всего коллектива, и от того как он её выполняет - насколько быстро и качественно, будет зависеть, в конечном итоге, «выживет» ли предприятие на рынке. По мнению одного из основоположников американского менеджмента Питера Друкера «Критерием гармонии внутри организации не может быть лишь сплочённость её членов; таким критерием является эффективность, а не конформизм. «Хорошие отношения между людьми», которые не основаны на удовлетворённости людей своей высокой производительностью и гармонией эффективного делового сотрудничества, на самом деле плохие отношения, а в результате появляется неудовлетворительный общий дух организации. Такие отношения не заставляют людей самосовершенствоваться. Скорее они заставляют их приспосабливаться и подстраиваться под других;

2. создать фактор семьи по средствам коммуникации и домашней обстановки. Необходимо дать понять любому сотруднику (личности) на предприятии, что работа - это его «второй дом». Коллеги, с которыми каждый сотрудник обменивается информацией, пьёт вместе чашку кофе, сидит в одном кабинете, или, в конце концов, просто работает должны быть одними из первых людей, к которым любой из работников того или иного предприятия сможет обратиться по любому вопросу. Руководитель предприятия должен суметь создать такой коллектив. Менеджер обязан приложить все усилия, чтобы его коллектив в дальнейшем только совершенствовался;

3. обращать внимание на психологическое состояние каждого сотрудника. Менеджер должен знать, что деятельность любого человека и её результаты обусловлены не только его устойчивыми индивидуальными качествами, но и в значительной степени временными сдвигами, которые возникают в его организме и определяются как психофизиологические состояния. Поэтому когда сотрудники находятся в эмоциональном и физическом упадке, у них снижается работоспособность. Именно в этот момент менеджер должен отреагировать незамедлительно и попытаться вывести человека из этого состояния;

4. уменьшить уровень стресса и возникновения конфликтных ситуаций. Каждый человек подвержен стрессу. Стресс обуславливается, прежде всего, факторами нашей повседневной жизни. Поэтому очень часто стрессовые ситуации приводят к возникновению конфликтов. Когда мы думаем о конфликте, на ум, как правило, приходят агрессия, угрозы, 
споры, вражда и т.д. Зачастую конфликт рассматривается как нежелательное явление, которого по возможности следует избегать, и считается, что его надо разрешать как можно скорее. Однако современная точка зрения заключается в том, что даже на предприятиях с эффективным менеджментом конфликты не только возможны, но и желательны. Конфликты часто не позитивны. В некоторых ситуациях они мешают удовлетворению потребностей индивидуума и достижению организационных целей. Например, если конфликт возник в результате воздействия на человека стрессовой ситуации, то здесь, по всей вероятности, нельзя говорить о положительном эффекте конфликта. В этой ситуации менеджеру рекомендуется погасить или, как минимум, смягчить конфликт, выявить его причину и вывести зачинщика конфликта на откровенную беседу. Возможно, благодаря ей человек успокоится и сможет благотворно и эффективно отработать оставшееся рабочее время. Но во многих ситуациях конфликт помогает представить разные мнения, обеспечивает дополнительной информацией, позволяет найти новые альтернативы и т.д. Иногда даже процесс конфликта повышает эффективность принятия групповых решений за счёт того что позволяет людям высказаться и тем самым удовлетворить личные потребности в уважении и власти. Необходимо также отметить, что приём нового сотрудника в организацию - это уже стресс как для самого сотрудника, так и для коллектива, в котором он будет работать. Поэтому менеджер должен подбирать новых сотрудников также исходя из сложившейся корпоративной культуры на предприятии. Кроме того, он должен помочь новому сотруднику сориентироваться на предприятии и социально адаптироваться;

5. развивать и мотивировать персонал. Путь к эффективному управлению человеком лежит через понимание его мотивации. Зная, что побуждает человека к деятельности, какие мотивы лежат в основе его действий, можно разработать эффективную систему форм и методов управления человеком. Доктор Р.А. Гендерсон в этой связи отмечает: «Надо помнить, что мотивация работника, прежде всего, связана с общей системой вознаграждений предприятия, которая может предложить огромный набор вознаграждений, привлекательных для работников. В то же время на нем происходит бесчисленное множество событий, совершенно непривлекательных для персонала (одни из них контролируются предприятием, другие - нет). Чтобы предприятие работало продуктивно, первая категория должна быть более мощной, чем вторая; и одним из таких факторов, причём контролируемых предприятием, является программа оплаты труда. Каждый, кто работал с людьми, признаёт, что факторов, позволяющих воздействовать на мотивацию каждого конкретного индивидуума, существует огромное множество. Более того, фактор, отлично работающий сегодня, завтра для того же человека может полностью утратить свою привлекательность. Никто точно не знает, как действует механизм мотивации, насколько мощным должен быть мотиватор и когда он срабатывает, не говоря уже о том, почему он срабатывает. Известно лишь то, что человек трудится ради денег и пакета прочих компенсаций 
и льгот. Деньгами работник в определённой степени распоряжается по своему усмотрению. И деньги, и другие компоненты системы оплаты труда обеспечивают ему необходимые условия для выживания, роста и отдыха сегодня, а также для защиты, развития и обеспечения благосостояния в будущем. Данные компоненты компенсации, конечно, не могут удовлетворить все потребности сотрудника, но предприятия предлагают буквально сотни других вознаграждений, которые способны усилить программу оплаты труда и зачастую удовлетворяют потребности, не удовлетворённые этой программой» [3].

Говоря о развитии персонала, следует отметить тот факт, что развитие является важнейшим условием успешного функционирования любого предприятия. Это особенно справедливо в современных условиях, когда ускорение научно-технического прогресса значительно убыстряет процесс устаревания профессиональных знаний и навыков. Поэтому менеджерам необходимо устраивать всевозможные тренинги, проводить семинары или отправлять персонал на курсы повышения квалификации.

Следует отметить, что менеджер работает с особым ресурсом - людьми. А человек - это действительно уникальный ресурс, общение с которым требует от менеджера совершенно особых качеств.

«Работать с человеком» означает воздействовать на него, развивать его. Направление такого развития определяет, будет ли этот человек - и как личность, и как ресурс - действительно развиваться или, наоборот, деградировать, причём до такой степени, когда его вообще невозможно будет рассматривать как ресурс. Это положение применимо не только к подчинённому, но и к самому менеджеру, но в несколько меньшей степени. Если менеджер воздействует на своих подчинённых (т.е. развивает их) в нужном направлении, помогая им совершенствоваться не только в своей профессии, но и как личностям, можно не сомневаться, что рано или поздно это окажет благотворное воздействие и на их профессиональные и личные качества.

Менеджер находится в постоянном контакте с людьми, которыми он управляет: он подбирает работу для этих людей, руководит её выполнением, готовит работников к выполнению порученной работы (в том числе и обучая их), оценивает результаты их труда, - в конце концов, он зачастую определяет будущее этих людей. Однако быть менеджером - это почти, то же, что быть родителем или наставником. А в этих отношениях одной лишь честности уже недостаточно. Самое главное в них - личная порядочность.

Таким образом, при формировании и развитии корпоративной культуры менеджер должен учитывать саму природу человеческих отношений, которые являются многогранными и основаны прежде всего на общении. При выполнении всех указанных задач каждый сотрудник предприятия будет развиваться, что приведет к повышению общей эффективности его функционирования. 


\section{Литература}

1. Балашов А.П. Основы менеджмента: [учеб. пособ.] / А.П. Балашов. - М.: Вузовский учебник, 2009. - 288 с.

2. Друкер Ф. Питер Практика менеджмента / П.В. Друкер. - М.: Вильямс, 2007. - $400 \mathrm{c}$.

3. Мескон М.Х. Основы менеджмента / М.Х. Мескон, М. Альберт, Ф. Хедоури. - М: Вильямс, 2008. - 670 с. 